\title{
Extracorporeal irradiation of tumorous calvaria: a case series
}

\author{
Daryoush Tavanaiepour, MBChB, ${ }^{1}$ William C. Broaddus, MD, PhD, ${ }^{2,3}$ \\ Theodore D. Chung, MD, PhD, ${ }^{4}$ Kathryn L. Holloway, MD, ${ }^{2}$ Michelle A. Proper, MD, ${ }^{3}$ \\ Sharon B. Wolber, $\mathrm{RN},{ }^{2}$ and Keith Neiderer, $\mathrm{CMD}^{3}$
}

1Department of Neurosurgery, University of Florida College of Medicine, Jacksonville, Florida; Departments of 2Neurosurgery and ${ }^{3}$ Radiation Oncology, Virginia Commonwealth University, Richmond, Virginia; and ${ }^{4}$ Division of Radiation Oncology, Georgia Regents University, Augusta, Georgia

\begin{abstract}
OBJECT When intracranial tumors invade the overlying skull, gross resection typically includes removal of the involved bone. Methods used to repair the resulting structural defect in the cranium include artificial prostheses, allogeneic bone grafts, and autoclaving the autologous graft. The authors have previously reported a case involving high-dose extracorporeal ionizing radiation to treat the tumorous calvaria intraoperatively, followed by reimplantation of the treated bone flap. In this paper the authors report the long-term follow-up of that case, as well as results of using extracorporeal irradiation of tumorous calvaria (EITC) for an additional 20 patients treated similarly.

METHODS The decision to undergo EITC was typically anticipated preoperatively, but determined intraoperatively, if upon inspection the bone flap was invaded by tumor. The bone flap was then delivered to the radiation oncology department, where a total dose of 120 Gy was delivered, using a clinical linear accelerator, over a period of approximately 15 minutes. After the intracranial tumor resection was completed, the irradiated craniotomy bone flap was reimplanted and the wound was closed in a standard fashion. A retrospective review of patients who had undergone EITC was performed for evidence of calvarial tumor recurrence or other complications.
\end{abstract}

RESULTS Since the originally reported case, 20 additional patients have received EITC during craniotomy for invasive tumors. Eighteen (86\%) of 21 patients were diagnosed with meningioma: $12(67 \%)$ with WHO Grade I, $5(28 \%)$ with WHO Grade II, and 1 with WHO Grade III (6\%). The remaining 3 patients presented with dural-based B-cell lymphoma with extensive adjacent bone invasion $(n=2)$ and metastatic adenocarcinoma of the lung $(n=1)$. Follow-up of the 21 patients ranged from 1 to 132 months, with a mean of 41 months and a median of 23 months. No patients have experienced tumor recurrence, infection associated with the treated calvaria, or evidence of bone flap resorption.

CONCLUSIONS Calvaria reconstructions represent an important component in structural and cosmetic outcome following craniectomy for tumorous bone. The authors' long-term experience with EITC has been excellent with no local tumor recurrence or complications. Therefore, EITC represents an excellent and efficient option for cranial reconstruction in such patients.

http://thejns.org/doi/abs/10.3171/2014.9.JNS131383

KEY WORDS tumorous calvaria; extracorporeal irradiation; meningioma; oncology

$\mathrm{W}$ HEN intracranial tumors invade the overlying skull, gross resection typically includes removal of the involved bone. Methods used to repair the resulting structural defect in the cranium include artificial prostheses, autologous and allogeneic bone grafts, and autoclaving the autologous graft. $8,23,29,31$ Although each of these techniques can be well tolerated and produce good cosmetic results, sterilizing and reimplanting the resected tumorous bone flap may provide optimum cosmetic result without immunological risk. ${ }^{29,31,33}$ The most widely reported technique for sterilizing a tumorous autologous bone graft is autoclaving, which destroys viable tumor cells, but may also denature proteins, increasing the likelihood of bone resorption..$^{6,74,29-31}$ We have previously reported

ABBREVIATION EITC = extracorporeal irradiation of tumorous calvaria.

SUBMITTED June 28, 2013. ACCEPTED September 29, 2014.

INCLUDE WHEN CITING Published online November 21, 2014; DOI: 10.3171/2014.9.JNS131383.

DISCLOSURE The authors report no conflict of interest concerning the materials or methods used in this study or the findings specified in this paper. 
a case using extracorporeal ionizing radiation to sterilize the tumorous calvaria intraoperatively, followed by reimplantation of the treated bone flap. ${ }^{17}$ In this paper we report the long-term follow-up of that case, as well as results of using extracorporeal irradiation of tumorous calvaria (EITC) for an additional 20 patients treated similarly.

\section{Methods}

After study approval by the Virginia Commonwealth University institutional review board, a retrospective chart review was performed. Clinical and demographic information was collected, as well as data from the following variables: rates of calvarial tumor recurrence, cosmetic results as determined by clinical examination, and bone resorption via imaging. The decision to perform EITC was typically anticipated preoperatively, but determined intraoperatively, if upon inspection the bone flap was invaded by tumor (Fig. 1). The bone flap was covered in wet gauze, wrapped to maintain sterility, and then delivered to the Radiation Oncology department. The bone flap was then inserted into the tray accessory mount on the clinical linear accelerator. One centimeter of bolus was placed above and below the bone flap and treatment was delivered with 6-MV photons to a total dose of 120 Gy prescribed to $\mathrm{D}_{\max }$ (the maximum point dose). Treatment time was 7 minutes, with the total process taking approximately 15 minutes. After the intracranial tumor resection was completed, the irradiated craniotomy bone flap was reimplanted and the wound was closed in a standard fashion.

\section{Results}

Since the originally reported patient (Case 1), 20 additional patients have received EITC (Table 1). The mean age of these 21 patients was 55 years old (range 24-79 years old), with 8 male and 13 female patients. The followup period of the 21 patients ranged from 1 to 132 months,
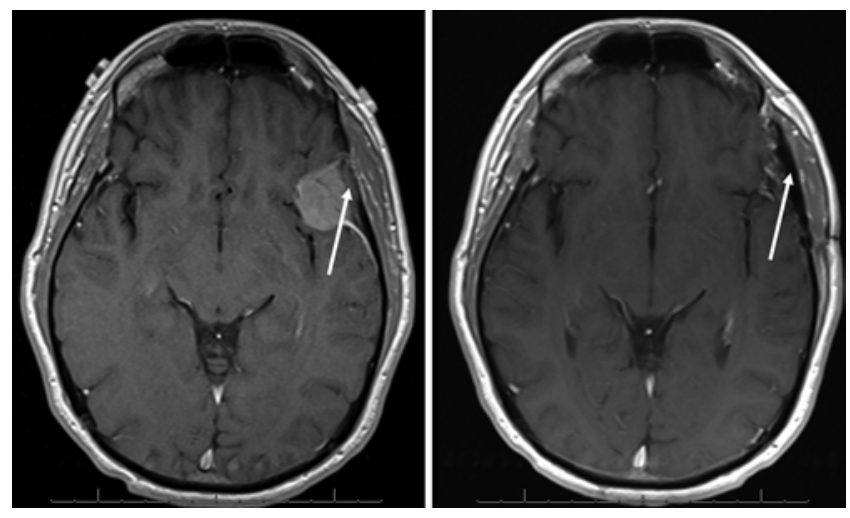

FIG. 1. Case 6. Left: Preoperative axial T1-weighted MR image after contrast administration in a 51-year-old man with an incidentally discovered left temporal meningioma. The arrow indicates contrast-enhancing tissue within the temporal bone. Adjacent images (not shown) demonstrated extracranial growth of tumor with partial invasion of the temporalis muscle, a finding that was confirmed intraoperatively. Right: Axial T1-weighted MR image after contrast administration from the analogous location obtained 49 months postoperatively, demonstrating a section of the bone flap (arrow) that had undergone EITC with no recurrence or calvaria resorption. with a mean of 41 months and a median of 23 months. No patients have experienced calvarial tumor recurrence, infection associated with the treated calvaria, or evidence of bone flap resorption (Figs. 1 and 2). As noted in Fig. 2, cranial flaps were sometimes less calcified than adjacent cranial bone by virtue of the prior presence of tumor involvement with reduction of bone calcium. One patient required reoperation for cranial hardware removal that was not related to EITC. This patient underwent postoperative local external beam radiation therapy for her dural lymphoma and subsequently suffered scalp atrophy, resulting in unacceptable protrusion of the cranial plating hardware. Eighteen $(86 \%)$ of 21 patients were diagnosed with meningioma: 12 (67\%) with WHO Grade I, 5 (28\%) with WHO Grade II, and 1 (6\%) with WHO Grade III. The remaining 3 patients presented with dural-based B-cell lymphoma with extensive adjacent bone invasion $(n=2)$ and metastatic adenocarcinoma of the lung $(n=1)$.

\section{Discussion}

We have performed EITC in 21 patients with a mean follow-up period of 41 months. Our results indicate no calvarial tumor recurrence, bone resorption requiring revision, or infection. The EITC procedure is feasible and can be performed in less than 20 minutes. Calvarial reconstruction in neurooncological surgery is an important component in structural and cosmetic outcome. However, managing tumor invasion of the calvaria can be challenging, especially when it involves the craniofacial or skull base region. Different options have been described, including artificial prostheses, autologous and allogeneic bone graft, and autoclaving the autologous bone graft. ${ }^{5,8,23,29-31}$

Numerous publications have confirmed that autologous bone grafting is considered the standard means of cranial reconstruction and is associated with lower complication

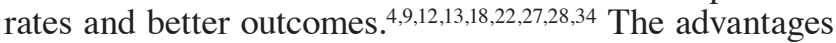
of autologous grafting include the avoidance of foreign material implantation, which may lead to inflammatory response, donor graft rejection, and higher infection rates. ${ }^{1,35}$ Furthermore, because the patient's own calvaria is used, it may lead to better structural and cosmetic outcome, reduced operative time, and lowered cost. 5,12,29-31,33 Autologous bone grafting options include heterotopic autologous bone graft and sterilized autologous bone graft. Heterotopic autologous bone graft requires harvesting of local unaffected calvaria, which may lead to donor site morbidity and increased operative time. ${ }^{29-31,33}$ The sterilized autologous bone graft technique destroys invaded tumorous cells and allows for reimplantation of the patient's calvaria flap. ${ }^{29-31,33}$ Traditionally, this has been accomplished by autoclaving the tumorous calvarial flap and was first described by Naffziger in $1936 .{ }^{19}$ Subsequent follow-up studies of this technique indicated no recurrence of tumor in the treated calvaria, but partial resorption was observed radiologically in $19 \%$ of the cases. ${ }^{29-31,33}$ Autoclaving has been shown to reduce torsional strength of up to $23 \%$ in mammalian diaphyseal bone. ${ }^{14}$ The structural degradation associated with autoclaving may compromise the structural integrity of the reimplanted autoclaved calvarial flap, although this has not been directly studied. 
TABLE 1. Clinical and demographic data of patients undergoing EITC in chronological order of surgery

\begin{tabular}{|c|c|c|c|c|c|}
\hline Case No. & $\begin{array}{c}\text { Age at Surgery } \\
\text { (yrs), Sex }\end{array}$ & Diagnosis & $\begin{array}{l}\text { Follow-Up } \\
\text { (mos) }\end{array}$ & $\begin{array}{l}\text { WHO } \\
\text { Grade }\end{array}$ & Comments \\
\hline 1 & $59, \mathrm{M}$ & Meningioma & 115.7 & I & Died of esthesioneuroblastoma not associated w/ flap \\
\hline 2 & $43, \mathrm{~F}$ & Lymphoma & 131.5 & & B-cell lymphoma, required hardware debridement \\
\hline 3 & $43, \mathrm{~F}$ & Meningioma & 106.2 & I & \\
\hline 4 & $39, F$ & Meningioma & 111.7 & I & \\
\hline 5 & $65, \mathrm{~F}$ & Lymphoma & 68.6 & & Diffuse B-cell lymphoma \\
\hline 6 & $51, \mathrm{M}$ & Meningioma & 48.8 & I & \\
\hline 7 & $67, \mathrm{M}$ & Meningioma & 43.9 & II & \\
\hline 8 & $63, \mathrm{M}$ & Meningioma & 29.3 & 1 & \\
\hline 9 & $66, F$ & Meningioma & 32.3 & I & \\
\hline 10 & $66, \mathrm{~F}$ & Meningioma & 33.5 & I & \\
\hline 11 & $33, F$ & Meningioma & 19.9 & I & \\
\hline 12 & $40, F$ & Meningioma & 23.4 & I & \\
\hline 13 & $24, F$ & Meningioma & 19.3 & I & \\
\hline 14 & $70, F$ & Meningioma & 14.5 & II & \\
\hline 15 & $51, \mathrm{M}$ & Metastatic & 13.3 & & Metastatic adenocarcinoma of the lung \\
\hline 16 & $67, \mathrm{~F}$ & Meningioma & 12.4 & I & \\
\hline 17 & $65, F$ & Meningioma & 10.2 & II & \\
\hline 18 & $66, \mathrm{M}$ & Meningioma & 3.7 & II & \\
\hline 19 & $79, \mathrm{M}$ & Meningioma & 1.1 & II & Died 1.1 mos postop \\
\hline 20 & $42, \mathrm{M}$ & Meningioma & 11.2 & I & \\
\hline 21 & $54, \mathrm{~F}$ & Meningioma & 2.6 & III & \\
\hline
\end{tabular}

An alternative sterilization technique to autoclaving is the use of ionizing radiation. This technique has been described in the maxillofacial and orthopedic literature for malignant musculoskeletal tumors, where the involved tumorous bone is resected, irradiated extracorporeally, and reimplanted. . $^{3,610,11,15,21,25,32}$ Recently, long-term studies (mean follow-up range of 45-66 months) indicated no local tumor recurrence at the extracorporeally irradiated skeletal bone. . $3,6,21^{3}$ Both animal and in vitro human studies directly comparing autoclaving with irradiation indicated a superior biomechanical profile and better incorporation of
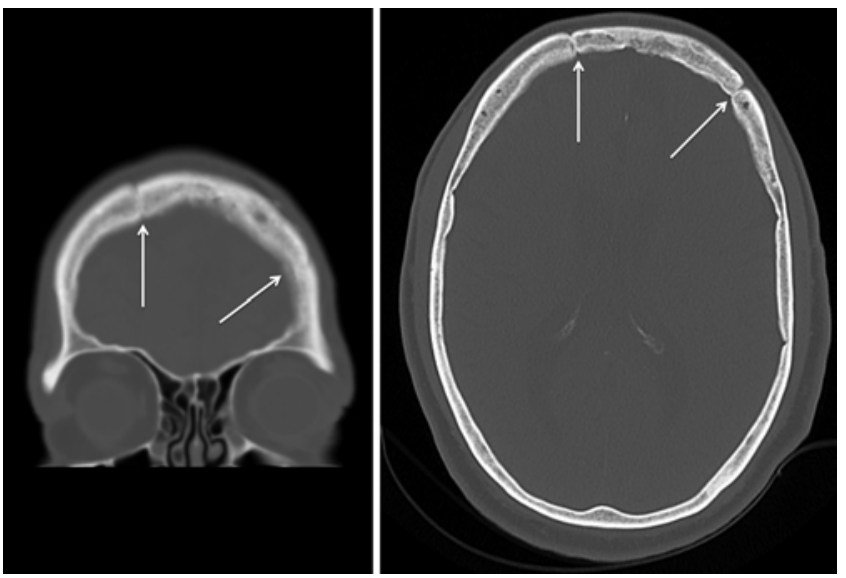

Fig. 2. Case 9. Coronal (left) and axial (right) CT scans with bone window settings obtained 24 months after surgery, demonstrating no significant resorption beyond that caused by the original bone invasion. Arrows delineate edges of the bone flap. the reimplanted bone with irradiation. ${ }^{6,7,24}$ When cadaveric bone flaps are used for implantation, they are irradiated to extremely high doses in the range of 1000-40,000 Gy to destroy antigens as well as infectious agents..$^{20}$ However, this can also denature structural proteins, which can impair mechanical integrity and promote demineralization or resorption of the treated calvaria. ${ }^{20}$ In the setting of autologous bone flaps, a smaller dose of radiation, between 50 and $200 \mathrm{~Gy}$, can provide complete tumor sterilization without the structural degradation caused by high-dose irradiation or autoclaving. Similar low doses between 50 and $300 \mathrm{~Gy}$ are also administered in orthopedic cases as described above. Animal studies utilizing intraoperative extracorporeal irradiation with lower doses have demonstrated excellent incorporation of the bone graft without structural integrity compromise.,26,32 Extracorporeal irradiation to sterilize tumorous autologous bone graft has been successfully used in malignant musculoskeletal tumors. However, to our knowledge, there is only 1 report utilizing this technique in neurooncological pathologies, ${ }^{16}$ aside from our original prior case report. ${ }^{17}$ The study by Lauritzen et al. performed EITC in 4 patients with meningioma with a limited 1-year follow-up. ${ }^{16}$ All patients tolerated the procedure well with no recurrence, but 1 patient did require revision of the bone flap due to resorption. The current study is a larger case series of 21 patients with a longer mean follow-up period of 41 months, with no complications or calvarial tumor recurrences. The main limitation of this study is the length of the follow-up period. The majority of the cases (57\%) were WHO Grade I meningiomas, which have an inherently low recurrence 
rate. Furthermore, calvarial resorption may take multiple years to become apparent. Therefore, a longer follow-up period may be necessary to determine the long-term outcome of EITC. Future studies investigating EITC in more aggressive pathologies and with longer follow-up periods are recommended.

\section{Conclusions}

Calvaria reconstruction following craniectomy for tumorous bone represents an important component in structural and cosmetic outcome. Our long-term experience with EITC has been excellent with no local tumor recurrence or complications. We believe that it represents an excellent and efficient option for cranial reconstruction in such patients.

\section{References}

1. Afifi AM, Gordon CR, Pryor LS, Sweeney W, Papay FA, Zins JE: Calcium phosphate cements in skull reconstruction: a meta-analysis. Plast Reconstr Surg 126:1300-1309, 2010

2. Anacak Y, Sabah D, Demirci S, Kamer S: Intraoperative extracorporeal irradiation and re-implantation of involved bone for the treatment of musculoskeletal tumors. J Exp Clin Cancer Res 26:571-574, 2007

3. Araki N, Myoui A, Kuratsu S, Hashimoto N, Inoue T, Kudawara I, et al: Intraoperative extracorporeal autogenous irradiated bone grafts in tumor surgery. Clin Orthop Relat Res (368): 196-206, 1999

4. Artico M, Ferrante L, Pastore FS, Ramundo EO, Cantarelli D, Scopelliti D, et al: Bone autografting of the calvaria and craniofacial skeleton: historical background, surgical results in a series of 15 patients, and review of the literature. Surg Neurol 60:71-79, 2003

5. Aydin S, Kucukyuruk B, Abuzayed B, Aydin S, Sanus GZ: Cranioplasty: review of materials and techniques. J Neurosci Rural Pract 2:162-167, 2011

6. Böhm P, Fritz J, Thiede S, Budach W: Reimplantation of extracorporeal irradiated bone segments in musculoskeletal tumor surgery: clinical experience in eight patients and review of the literature. Langenbecks Arch Surg 387:355-365, 2003

7. Böhm P, Scherer MA: Incorporation of devitalised autografts in dogs. Int Orthop 21:283-290, 1997

8. Chen TM, Wang HJ: Cranioplasty using allogeneic perforated demineralized bone matrix with autogenous bone paste. Ann Plast Surg 49:272-279, 2002

9. Cutting CB, McCarthy JG, Berenstein A: Blood supply of the upper craniofacial skeleton: the search for composite calvarial bone flaps. Plast Reconstr Surg 74:603-610, 1984

10. Hamaker RC: Irradiation autogenous mandibular grafts in primary reconstructions. Laryngoscope 91:1031-1051, 1981

11. Hamaker RC, Singer MI, Shockley WW, Pugh N, Shidnia H: Irradiated mandibular autografts. Cancer 52:1017-1021, 1983

12. Hayward RD: Cranioplasty: don't forget the patient's own bone is cheaper than titanium. Br J Neurosurg 13:490-491, 1999

13. Jackson IT, Pellett C, Smith JM: The skull as a bone graft donor site. Ann Plast Surg 11:527-532, 1983

14. Köhler P, Kreicbergs A, Strömberg L: Physical properties of autoclaved bone. Torsion test of rabbit diaphyseal bone. Acta Orthop Scand 57:141-145, 1986

15. Komender J: Evaluation of radiation-sterilized bone and clinical use. Acta Med Pol 19:277-281, 1978

16. Lauritzen C, Kocabalkan O, Sugawara Y, Sahlin P, Olsson R:
Reuse of tumorous calvarial bone after gamma irradiation. $\mathbf{J}$ Craniofac Surg 9:459-463, 1998

17. Manning MA, Cardinale RM, Schmidt-Ullrich RK, Kavanagh BD, Wornom IL III, Broaddus WC: Extracorporeal irradiation of tumorous calvaria. Case report. J Neurosurg 93:494-497, 2000

18. Moreira-Gonzalez A, Jackson IT, Miyawaki T, Barakat K, DiNick V: Clinical outcome in cranioplasty: critical review in long-term follow-up. J Craniofac Surg 14:144-153, 2003

19. Naffziger HC: The restoration of defects in the skull with special reference to the management of intrinsic tumors of the skull and certain types of localized osteomyelitis. Ann Surg 104:321-331, 1936

20. Nguyen H, Morgan DA, Forwood MR: Sterilization of allograft bone: effects of gamma irradiation on allograft biology and biomechanics. Cell Tissue Bank 8:93-105, 2007

21. Poffyn B, Sys G, Mulliez A, Van Maele G, Van Hoorebeke L, Forsyth R, et al: Extracorporeally irradiated autografts for the treatment of bone tumours: tips and tricks. Int Orthop 35:889-895, 2011

22. Prolo DJ, Rodrigo JJ: Contemporary bone graft physiology and surgery. Clin Orthop Relat Res (200):322-342, 1985

23. Rotaru H, Stan H, Florian IS, Schumacher R, Park YT, Kim SG, et al: Cranioplasty with custom-made implants: analyzing the cases of 10 patients. J Oral Maxillofac Surg 70:e169-e176, 2012

24. Singh VA, Nagalingam J, Saad M, Pailoor J: Which is the best method of sterilization of tumour bone for reimplantation? A biomechanical and histopathological study. Biomed Eng Online 9:48, 2010

25. Spira E, Brenner HT, Lubin E: Extracorporeal irradiation of malignant bone tumors, in Chapchal G (ed): Operative Treatment of Bone Tumors. Stuttgart: Thieme, 1970, pp 136-140

26. Takahashi S, Sugimoto M, Kotoura Y, Yamamuro T, Oka M, Shibamoto Y, et al: Incorporation of cortical bone autografts following intraoperative extracorporeal irradiation in rabbits. Int J Radiat Oncol Biol Phys 21:1221-1230, 1991

27. Tessier P, Kawamoto H, Matthews D, Posnick J, Raulo Y, Tulasne JF, et al: Autogenous bone grafts and bone substitutes-tools and techniques: I. A 20,000-case experience in maxillofacial and craniofacial surgery. Plast Reconstr Surg 116 (5 Suppl):6S-24S, 2005

28. Tessier P, Kawamoto H, Posnick J, Raulo Y, Tulasne JF, Wolfe SA: Complications of harvesting autogenous bone grafts: a group experience of 20,000 cases. Plast Reconstr Surg 116 (5 Suppl):72S-73S, 2005

29. Vanaclocha V, Bazan A, Saiz-Sapena N, Paloma V, Idoate M: Use of frozen cranial vault bone allografts in the repair of extensive cranial bone defects. Acta Neurochir (Wien) 139:653-660, 1997

30. Vanaclocha V, Saíz-Sapena N: Surgical treatment of anterior skull base tumours. Acta Neurochir (Wien) 139:857-868, 1997

31. Vanaclocha V, Sáiz-Sapena N, García-Casasola C, De Alava E: Cranioplasty with autogenous autoclaved calvarial bone flap in the cases of tumoural invasion. Acta Neurochir (Wien) 139:970-976, 1997

32. Voggenreiter G, Ascherl R, Blümel G, Schmit-Neuerburg KP: Extracorporeal irradiation and incorporation of bone grafts. Autogeneic cortical grafts studies in rats. Acta Orthop Scand 67:583-588, 1996

33. Wester K: Cranioplasty with an autoclaved bone flap, with special reference to tumour infiltration of the flap. Acta Neurochir (Wien) 131:223-225, 1994

34. Whitaker LA, Munro IR, Salyer KE, Jackson IT, OrtizMonasterio F, Marchac D: Combined report of problems and complications in 793 craniofacial operations. Plast Reconstr Surg 64:198-203, 1979 
35. Wong RK, Gandolfi BM, St-Hilaire H, Wise MW, Moses M: Complications of hydroxyapatite bone cement in secondary pediatric craniofacial reconstruction. J Craniofac Surg 22:247-251, 2011

\section{Author Contributions}

Conception and design: Broaddus, Tavanaiepour, Chung. Acquisition of data: all authors. Analysis and interpretation of data: Broaddus, Tavanaiepour. Drafting the article: Broaddus, Tavanaiepour. Critically revising the article: all authors. Reviewed submitted version of manuscript: all authors. Approved the final version of the manuscript on behalf of all authors: Broaddus. Statistical analysis: Broaddus, Tavanaiepour.
Administrative/technical/material support: Broaddus, Tavanaiepour. Study supervision: Broaddus.

\section{Supplemental Information}

Previous Presentation

Part of the results section of this manuscript was previously presented as an abstract poster at the 2011 CNS Annual Meeting in Washington, DC.

\section{Correspondence}

William C. Broaddus, Department of Neurosurgery, Medical College of Virginia, Virginia Commonwealth University, Box 980631, Rm. 650 Ambulatory Care Center, 417 N. 11th St.

Richmond, VA 23298-0631. email: wbroaddus@mcvh-vcu.edu. 